\title{
Suicide vs Homicide Firearm Injury Patterns, Weapons, and Mortality: A Study of the National Trauma Data Bank (NTDB)
}

Christopher Foote ( $\nabla$ christopher.foote@uhsinc.com )

South Texas Health System - McAllen Medical Center

\section{Xuan-Lan Doan}

Valley Health System

Cheryl Vanier

Touro University Nevada

\section{Bianca Cruz}

South Texas Health System - McAllen Medical Center

\section{Babak Sarani}

George Washington University

\section{Carlos Palacio}

South Texas Health System - McAllen Medical Center

\section{Research Article}

Keywords: Firearms, Injury, Suicide, Homicide

Posted Date: February 22nd, 2022

DOI: https://doi.org/10.21203/rs.3.rs-1272923/v2

License: (a) (i) This work is licensed under a Creative Commons Attribution 4.0 International License.

Read Full License 


\section{Abstract}

\section{Background:}

Firearm related mortality in the USA surpassed all other developed countries. This study hypothesizes that injury patterns, weapon type, and mortality differ between suicide groups as opposed to homicide.

\section{Methods:}

The American College of Surgeons National Trauma Database was queried from January 2017 to December 2019. All firearm related injuries were included, and weapon type was abstracted. Differences between homicide and suicide groups by sex, age, race, and injury severity were compared using a MannWhitney test for numerical data and Fisher's exact test for categorical data. The association between weapon type and mortality relative to suicide as opposed to homicide was assessed in Fisher's exact tests. Significance was defined as $p<0.05$.

\section{Results:}

There were 100,031 homicide and 11,714 suicide subjects that met inclusion criteria. Homicides were mostly assault victims (97.6\%), male (88\%), African-American (62\%), had less severe injury (mean ISS 12.07) and a median age of 20 years old (IQR: $14,30, p<0.01)$. Suicides were mostly male ( $83 \%)$, white (79\%), had more severe injury (mean ISS 20.73), and a median age of 36 years old (IQR: 19, 54, $p<0.01$ ). Suicide group had higher odds of head/neck $(O R=13.6)$ or face $(O R=5.7)$ injuries, with lower odds of injury to chest $(\mathrm{OR}=0.55)$, abdominal or pelvic contents $(\mathrm{OR}=0.25)$, extremities or pelvic girdle $(\mathrm{OR}=0.15)$, or superficial soft tissue $(\mathrm{OR}=0.32)$. Mortality rate was higher for suicide group ( $44.8 \%$; $95 \%$ confidence interval (Cl): $43.9 \%, 45.7 \%)$ compared to the homicide group (11.5\%; $95 \% \mathrm{Cl}: 11.3 \%, 11.7 \%)$.

\section{Conclusions:}

Suicide had higher mortality, more severe injuries, and more head/neck/facial injuries than homicide. Majority of suicides were with handguns.

\section{Level of Evidence: Level IV}

\section{Background}

Firearm related injury is a complex public health issue worldwide. While firearm death rates declined from 2003-2015 among most high-income countries, the United States (US) increased from 10.2 to 11.2 per 100,000 people [1]. In 2015, the overall US firearm death rate was 11.4 times higher than 28 other high income countries combined, thereby giving the US the highest rates of firearm homicide, firearm suicide, and unintentional firearm related deaths per 100,00 people [1].

Firearm homicide and suicide are among the top ten causes of injury deaths in the US. In 2018 there were 38,390 deaths related to firearms suicide and homicide combined which surpassed unintentional falls and 
motor vehicle collisions. In 2019, firearm homicide and suicide was the leading cause of violence-related injury death among persons 15-34 years of age [2]. Suicide and homicide accounted for $8.1 \%$ and $5.1 \%$ years of potential life lost, respectively, before the age of 65 in 2019 [2].

Firearm injuries may be preventable, however, the issues are multi-faceted. Access to firearms and inadvertent discharge have been readily discussed in the literature. Intentional firearm injury that does not immediately lead to death comes with significant morbidity, recovery, and impact on social and interpersonal needs of the patient. In an attempt to hopefully prevent future occurrences, we must try to understand the nature and extent of the problem. This study seeks to compare the differences in population, substance use, injury patterns, weapon type, and in-hospital mortality between suicide and homicide groups that reach trauma centers for care using a large nationally reported trauma database.

\section{Methods}

A retrospective study from January 2017 to December 2019 was performed using the American College of Surgeons (ACS) National Trauma Data Bank (NDTB) [3]. All methods were performed in accordance with the relevant guidelines and regulations. This study does not require any approval by an Institutional Review Board as the NTDB contains only publically available, de-identified data compiled from millions of electronic records out of hundreds of trauma centers across the US. The NTDB collects data from patients who present to all level I and level II trauma centers. Level III and IV trauma centers can participate in the data bank voluntarily. All data are de-identified and aggregated, and searchable through the American College of Surgeons. With more than 7.5 million electronic records, the NTDB is the world's largest trauma data repository [4] and the most robust source of clinical information for firearms injury [5].

All firearm related injuries and weapon type were abstracted using ICD-10 codes (W32-W34.XXX Firearm injury: Unintentional (unintentional shooting, fatal or non-fatal), X72-74.XXX Firearm injury: Self-harm (gun suicide, attempted or completed), X93-X95.XXX Firearm injury: Assault (gun homicide, attempted or completed), Y22-24.XXX Firearm injury: Undetermined intent (unknown cause, fatal or non-fatal), Y35.XXX Firearm injury: Justifiable shooting (legal intervention, fatal or non-fatal), Y36.4XX Firearm injury: War operations (war shooting, fatal or non-fatal)). Division of groups were made for comparison simplicity with 'Homicide' including firearm injuries inflicted onto the patient, and 'Suicide' including firearm injuries that were purposely self-inflicted.

The demographic information and injury severity of homicide and suicide groups were compared using a Mann-Whitney test for numerical data and Fisher's exact test for categorical data. Logistic regression was used to determine the ways that injury location, injury type/severity, and detected drugs were associated with suicide as opposed to homicide. The association between weapon type and mortality relative to suicide as opposed to homicide was assessed in Fisher's exact tests. Significance was defined as $p<0.05$.

\section{Results}


During the study period, 100,031 homicides and 11,714 suicides were identified. The homicide group was composed of individuals who were categorized as assault $(n=97,639)$, legal intervention $(n=2,303)$, military operations $(n=9)$, terrorism $(n=76)$, or war operations $(n=4)$. The suicide group included the Intentional Self-Harm categories as described above $(n=11,714)$. Accidental Discharge $(n=18,920)$ was not included as this topic has been heavily reported and analyzed in the literature. Accidental Malfunction $(n=397)$, and Undetermined Intent $(2,748)$ categories were not included in the analysis as there was no significant statistical value.

Demographics between the two groups differed in several ways. Median age for suicide subjects (36, IQR: $19,54)$ was 16 years older than for homicide subjects $(20$, IQR: 14,30$)$ (Table 1). African-American subjects made up $62 \%$ of the homicide group and only $10 \%$ of the suicide group. Asian, American Indian, and White subjects had higher percentages in the suicide group than the homicide group (Table 1). Males comprised the vast majority of both the homicide and suicide groups, $88 \%$ and $83 \%$, respectively.

Table 1

Demographics about subjects included in the study.

\begin{tabular}{|c|c|c|c|c|c|}
\hline & \multicolumn{2}{|c|}{ Homicide } & \multicolumn{3}{|c|}{ Suicide } \\
\hline Number of subjects & \multicolumn{2}{|c|}{100,031} & \multicolumn{2}{|l|}{11,714} & p-value \\
\hline Age (median, IQR) & \multicolumn{2}{|c|}{$20(14,30)$} & \multicolumn{2}{|c|}{$36(19,54)$} & $<0.001$ \\
\hline Maximum AIS severity & \multicolumn{2}{|l|}{$3(2,3)$} & \multicolumn{2}{|l|}{$5(3,5)$} & $<0.001$ \\
\hline Sex (\%female) & $12.0 \%$ & 12,233 & $17.0 \%$ & 2,044 & $<0.001$ \\
\hline ASIAN & $0.7 \%$ & 675 & $1.0 \%$ & 122 & $<0.001$ \\
\hline PACIFIC ISLANDER & $0.2 \%$ & 234 & $0.2 \%$ & 24 & 0.611 \\
\hline RACEOTHER & $9.1 \%$ & 9,085 & $5.3 \%$ & 619 & $<0.001$ \\
\hline AMERICAN INDIAN & $0.7 \%$ & 657 & $1.1 \%$ & 125 & $<0.001$ \\
\hline AFRICAN AMERICAN & $62.3 \%$ & 62,331 & $10.1 \%$ & 1,178 & $<0.001$ \\
\hline WHITE & $24.9 \%$ & 24,877 & $78.9 \%$ & 9,246 & $<0.001$ \\
\hline RACE Unavailable & $1.0 \%$ & 970 & $1.2 \%$ & 144 & 0.009 \\
\hline RACE Unknown & $1.7 \%$ & 1,682 & $2.5 \%$ & 297 & $<0.001$ \\
\hline
\end{tabular}

A comparison of Abbreviated Injury Scale (AIS) scores between both groups demonstrated more severe injuries within the suicide group than the homicide group (Table 1). Superficial soft tissue injuries were the most common pattern of injury between both groups, however, some significant differences emerged between the two groups (Table 2). Higher rates of injuries to the extremities or pelvic girdle were observed 
among homicide subjects, while higher rates of injuries to the head or neck were observed among suicide subjects. Considering head or neck injuries occurred most frequently among suicide subjects, a greater incidence of a GCS less than 13, respiratory rate less than 10 or more than 29 (breaths per minute), and skull fracture would be expected in this group (Table 3). The homicide subjects had higher odds of having low systolic blood pressure, penetrating injuries, long bone injury, crush injury, amputation, and paralysis.

Table 2

Location of injuries for homicide and suicide groups.

\begin{tabular}{|lllllll|}
\hline & Odds Ratio & $95 \%$ Cl & \multicolumn{2}{c|}{ Suicide } & \multicolumn{2}{c|}{ Homicide } \\
\hline Head or Neck & 13.58 & $(12.79,14.42)$ & 7,904 & $67 \%$ & 13,253 & $13 \%$ \\
\hline Face & 5.72 & $(5.38,6.07)$ & 3,904 & $33 \%$ & 8,044 & $8 \%$ \\
\hline Chest & 0.55 & $(0.52,0.58)$ & 1,800 & $15 \%$ & 24,852 & $25 \%$ \\
\hline Abdominal or pelvic contents & 0.25 & $(0.23,0.27)$ & 930 & $8 \%$ & 25,420 & $25 \%$ \\
\hline Extremities or pelvic girdle & 0.15 & $(0.14,0.16)$ & 836 & $7 \%$ & 33,711 & $34 \%$ \\
\hline Superficial Soft Tissue & 0.32 & $0.31,0.34$ & 4,660 & $40 \%$ & 67,091 & $67 \%$ \\
\hline $\begin{array}{l}\text { The odds ratio (OR) and its 95\% confidence interval (Cl) are shown, along with the number and percent } \\
\text { of homicides and suicides who had injuries in each location. }\end{array}$ & & & & \\
\hline
\end{tabular}


Table 3

Details and severity of injuries for homicide and suicide groups.

\begin{tabular}{|c|c|c|c|c|c|c|}
\hline & Odds Ratio & $95 \% \mathrm{Cl}$ & \multicolumn{2}{|c|}{ Suicide } & \multicolumn{2}{|c|}{ Homicide } \\
\hline GCS $\leq 13$ & 5.59 & $(5.16,6.05)$ & 2,327 & $19.9 \%$ & 4,249 & $4.2 \%$ \\
\hline $\mathrm{SBP}<30$ & 2.24 & $(2.01,2.50)$ & 766 & $6.5 \%$ & 3,026 & $3.0 \%$ \\
\hline 10RR29 & 3.98 & $(3.57,4.44)$ & 961 & $8.2 \%$ & 2,196 & $2.2 \%$ \\
\hline PEN & 1.38 & $(1.25,1.53)$ & 4,363 & $37.2 \%$ & 30,044 & $30.0 \%$ \\
\hline CHEST & 2.16 & $(1.34,3.47)$ & 25 & $0.2 \%$ & 99 & $0.1 \%$ \\
\hline LONGBONE & 0.20 & $(0.05,0.83)$ & 2 & $0.0 \%$ & 86 & $0.1 \%$ \\
\hline CRUSHED & 0.44 & $(0.22,0.89)$ & 9 & $0.1 \%$ & 173 & $0.2 \%$ \\
\hline AMPUTATION & 0.29 & $(0.04,2.28)$ & 1 & $0.0 \%$ & 29 & $0.0 \%$ \\
\hline PELVIC & 0.89 & $(0.34,2.35)$ & 5 & $0.0 \%$ & 48 & $0.0 \%$ \\
\hline SKULLFRACTURE & 18.60 & $(15.78,21.82)$ & 568 & $4.8 \%$ & 274 & $0.3 \%$ \\
\hline PARALYSIS & 0.27 & $(0.12,0.58)$ & 7 & $0.1 \%$ & 223 & $0.2 \%$ \\
\hline \multicolumn{7}{|c|}{$\begin{array}{l}\text { The odds ratio (OR) and its } 95 \% \text { confidence interval (CI) are shown, along with the number and percent } \\
\text { of subjects within homicide and suicide groups for each. GCS (Glasgow Coma Scale), SBP (Systolic } \\
\text { Blood Pressure), } 10 \text { RR29 (abnormal respiratory rate less than } 10 \text { or greater than 29), PEN (Penetrating } \\
\text { injury). }\end{array}$} \\
\hline
\end{tabular}

Homicide and suicide group subjects also differed by substances found in their system (Table 4). Suicide subjects most commonly had no substances in their system. When illicit/recreational drugs were involved, suicide subjects were more likely to have barbiturates, benzodiazepines, tricyclic antidepressants, or 'other' drugs in their system. Illicit/recreational drugs such as amphetamines, cocaine, ecstasy (MDMA), opioids, phencyclidine (PCP), and cannabinoids were more likely observed in the homicide group with the most common being cannabinoids. 
Table 4

Drugs observed in homicide and suicide groups

\begin{tabular}{|lllllll|}
\hline & Odds Ratio & $95 \%$ Cl & Suicide & \multicolumn{3}{c|}{ Homicide } \\
\hline AMPHETAMINE & 0.83 & $(0.75,0.92)$ & 591 & $5.0 \%$ & 5,999 & $6.0 \%$ \\
\hline BARBITURATE & 2.82 & $(2.08,3.81)$ & 115 & $1.0 \%$ & 351 & $0.4 \%$ \\
\hline BENZODIAZEPINES & 1.61 & $(1.47,1.77)$ & 796 & $6.8 \%$ & 4,326 & $4.3 \%$ \\
\hline COCAINE & 0.67 & $(0.60,0.75)$ & 464 & $4.0 \%$ & 5,798 & $5.8 \%$ \\
\hline METHAMPHETAMINE & 0.97 & $(0.80,1.17)$ & 179 & $1.5 \%$ & 1,576 & $1.6 \%$ \\
\hline ECSTASY & 1.6 & $(1.04,2.46)$ & 56 & $0.5 \%$ & 300 & $0.3 \%$ \\
\hline METHADONE & 1.42 & $(0.88,2.29)$ & 31 & $0.3 \%$ & 186 & $0.2 \%$ \\
\hline OPIOID & 0.71 & $(0.62,0.81)$ & 320 & $2.7 \%$ & 3,810 & $3.8 \%$ \\
\hline OXYCODONE & 0.9 & $(0.69,1.19)$ & 70 & $0.6 \%$ & 661 & $0.7 \%$ \\
\hline PHENCYCLIDINE & 0.49 & $(0.33,0.74)$ & 32 & $0.3 \%$ & 554 & $0.6 \%$ \\
\hline TCA & 2.47 & $(1.53,3.98)$ & 28 & $0.2 \%$ & 97 & $0.1 \%$ \\
\hline CANNABINOID & 0.52 & $(0.49,0.56)$ & 1,348 & $11.5 \%$ & 20,002 & $20.0 \%$ \\
\hline OTHER & 1.38 & $(1.05,1.81)$ & 68 & $0.6 \%$ & 421 & $0.4 \%$ \\
\hline NONE & 2.27 & $(2.16,2.39)$ & 2,711 & $23.1 \%$ & 11,713 & $11.7 \%$ \\
\hline $\begin{array}{l}\text { The odds ratio (OR) and its } 95 \% \text { confidence interval (CI) are shown, along with the number and percent } \\
\text { of homicides and suicides who had a drug in their system. (TCA: tricyclic antidepressants) }\end{array}$ & \\
\hline
\end{tabular}

In-hospital mortality rate was significantly higher $(\mathrm{OR}=6.2, \mathrm{P}<0.001)$ within the suicide group $(44.8 \%$, $95 \% \mathrm{Cl}: 43.9 \%, 45.7 \%)$ compared to the homicide group (11.5\%, 95\% Cl: $11.3 \%, 11.7 \%)$. Most homicide and suicide incidents involved a handgun or an unspecified firearm (Table 5). In the suicide group, overall inhospital mortality rates were high, between $44-50 \%$ for firearms and handguns versus air guns and shotguns at $4-29 \%$ (Table 5). This is a stark contrast to the homicide group with an overall in-hospital mortality rate of $11.5 \%$ regardless of weapon type. 
Table 5

Groups differ in the involvement of weapon types and resulting mortality by group.

\begin{tabular}{|c|c|c|c|c|c|c|c|}
\hline & \multicolumn{3}{|l|}{ Homicide } & \multicolumn{4}{|l|}{ Suicide } \\
\hline & $\begin{array}{l}\text { Total } \\
\text { Incidents }\end{array}$ & Mortalities & $\begin{array}{l}\% \\
\text { mortality }\end{array}$ & $\begin{array}{l}\text { Total } \\
\text { Incidents }\end{array}$ & Mortalities & $\begin{array}{l}\% \\
\text { mortality }\end{array}$ & $\begin{array}{l}\mathrm{P} \text { - } \\
\text { value }\end{array}$ \\
\hline Handgun & 36,555 & 4,075 & $11.1 \%$ & 7,735 & 3,602 & $46.6 \%$ & $\begin{array}{l}<.001 \\
0.001\end{array}$ \\
\hline Other firearm & 3,353 & 399 & $11.9 \%$ & 454 & 200 & $44.1 \%$ & $\begin{array}{l}<.001 \\
0.001\end{array}$ \\
\hline $\begin{array}{l}\text { Unspecified } \\
\text { firearm }\end{array}$ & 56,036 & 6,795 & $12.1 \%$ & 2,342 & 1,165 & $49.7 \%$ & $\begin{array}{l}<.001 \\
0.001\end{array}$ \\
\hline Shotgun & 1,719 & 123 & $7.2 \%$ & 558 & 116 & $20.8 \%$ & $\begin{array}{l}< \\
0.001\end{array}$ \\
\hline Hunting rifle & 356 & 36 & $10.1 \%$ & 351 & 103 & $29.3 \%$ & $\begin{array}{l}< \\
0.001\end{array}$ \\
\hline Airgun & 685 & 4 & $0.6 \%$ & 99 & 4 & $4.0 \%$ & 0.013 \\
\hline \multirow[t]{2}{*}{ Weapons_other } & 1,327 & 112 & $8.4 \%$ & 175 & 59 & $33.7 \%$ & $\begin{array}{l}<.001 \\
0.001\end{array}$ \\
\hline & 100,031 & 11,544 & $11.5 \%$ & 11,714 & 5,249 & $44.8 \%$ & \\
\hline
\end{tabular}

\section{Discussion}

This retrospective study adds to the body of literature concerning gunshot wounds by analyzing data from the NTDB from all trauma centers from within the country representing the highest rates of firearm deaths. In observing the data from patients who arrive to trauma centers alive, we might glean information that may direct us in helping those who can benefit from clinician intervention. Similar to previous publications, we found the suicide group comprised of mostly older white males. A mortality study performed by Branas et al. found most of the suicides were male, older (>35 years), white, and at least half were unmarried. Their homicide group was also comprised of younger, African-American males [6]. A study on gun violence by Manley et al. also discovered the majority of their patients injured with a documented firearm were African American males, with a median age of 28 , and aggravated assault as the most common circumstance [7]. A retrospective study on interpersonal violence at a Level I trauma center by Livingston et al. also found a significant and disproportionate representation by young African American males [8].

Firearm-related injuries are a significant public health crisis in the US, contributing to disability, loss of productivity, and tragically, death [9]. This retrospective analysis of the severity of injury and in-hospital 
mortality found the suicide group experienced more severe injuries in addition to increased mortality compared to the homicide group. Suicide attempts have a case fatality rate of nearly $90 \%$ [10]. An epidemiological trend study on firearm mortality in the US by Goldstick et al., evaluated data from 2006 to 2014 , and noted that suicides were consistently the majority of firearm related deaths ranging from 54.6$63.7 \%$, respectively [11].

Firearm related injuries to the head are a leading cause of TBI related morbidity and mortality, with one third of patients arriving to the hospital alive, ultimately succumbing to their injury [9]. The remaining two thirds of these will then go on to have TBI with potentially prolonged rehabilitation, motor deficits, cognitive disability, etc that will worsen the quality of their daily lives after attempting to end it. In this study, head and neck injuries were more commonly associated with suicide. Self-inflicted gunshot wounds are more likely to involve the head and neck regions and often result in death [12]. In this study, extremity injuries were more commonly observed in the homicide group. This group will also likely need additional rehabilitation, possible prosthesis, and will impact their functionality. Fowler et al., described similar results for patients who arrived to the hospital due to unintentional circumstances [9]. Handguns account for most of the firearm related injuries in this retrospective study. A study evaluating homicidal gunshot wounds at a single Level 1 trauma center in Kansas found handguns to be the most common weapon of choice in their patients [13]. Another study in a rural Midwest level 1 trauma center performed by Guetschow et al. also observed handguns to be the most common weapon type for unintentional firearm related injuries [14].

There are multiple modifiable risk factors for firearm suicide. A recent study from the National Violent Death Reporting System (NVDRS) found that $54 \%$ of suicide victims did not have a known mental illness [5]. This number may be due to lack of access to mental health resources, lack of financial resources to obtain therapeutic medications, or missed opportunities for treatment of undiagnosed illness. This retrospective study found that detectable antidepressants had much higher odds (OR 2.47, 95\% Cl: 1.53 , 3.98) in the suicide group than homicide. Access to highly lethal means, in the setting of acute life stressors and substance use, even without prior suicidal ideation, may explain the increase risk of impulsivity and suicide by firearm [5]. Conversely, risk factors for homicide include involvement in gang activity and illegal firearm possession along with socioeconomic risk factors such as income and social inequality [5]. Our study found the homicide group was more likely to have used illicit/recreational drugs. Initiating substance use counseling on index admission rather than having planned follow-up as outpatient after discharge may reduce subsequent recurrence. Psychiatric services with possible initiation of appropriate antidepressants in suicidal patients in concordance with substance use counseling may benefit those who were missed, self-medicating, undiagnosed, or needing appropriate care while recovering from their injuries might also improve recovery and long-term outcomes

Access to firearms has been shown, and well described in the literature, to be associated with increased risk factor for firearm suicide related injuries [15]. In fact, after controlling for confounding factors such as unemployment, mental illness, poverty, illicit drug and alcohol dependence, firearm availability increases the risk of suicide [16]. A meta-analysis on accessibility of firearms and risk for suicide and homicide 
reported a significant increase in the odds of suicide among patients with access to firearms compared to those who did not [17]. Background checks are an evidence-based practice that reduce firearm violence and mortality. Healthcare providers can have a positive impact in preventing firearm related injury by intentionally engaging in discussion with patients about firearm ownership and safety [15].

A limitation of this article it is the retrospective nature of the paper. Even though the data from NTDB is a robust source for firearm injuries, it does not include data from acute care facilities that are not certified trauma centers, patients discharged from emergency departments, and does not speak to the circumstances preceding the injuries [5]. Our study also takes illicit and/or prescribed psychoactive substances into account, but did not evaluate the effect of alcohol. There is a breadth of literature discussing the relationship between ethanol use and both suicidality and homicides and may have confounded our data. Although we are unable to perform a cost analysis, Cook et al., estimated the overall annual cost of firearm injuries to be $\$ 2.3$ billion USD [18]. A more recent estimate of the societal cost of firearm injury ranks eighth on the US government expenditure list in 2010 , with a cost of $\$ 174.1$ billion USD [19].

\section{Conclusions}

This retrospective study found, firearm suicide injuries group had a higher in-hospital mortality and higher injury severity when compared to the firearm homicide group. Suicide attempts reaching the hospital alive tended to be older white males, have more frequent severe head and neck injuries, and more likely to have antidepressants detectable on routine drug screens. Homicide patients tended to be younger AfricanAmerican males, have more extremity injuries, and found to have illicit/recreational substances detectable on drug screens. The majority of suicides and homicides were committed with handguns. Several risk factors for gun violence may be mitigated as clinicians during the index admission to assist in recovery.

\section{Declarations}

\section{Ethics approval and consent to participate}

Not applicable as it was a database review.

\section{Consent for publication}

All authors have read and approved final version of this work. No waiver of consent was necessary from patients as was de-identified data review.

\section{Availability of data and materials}

All data was obtained via the American College of Surgeons (ACS) National Trauma Database (NTDB). The datasets used and/or analyzed during the current study are available from the corresponding author 
on reasonable request. Data was obtained via the ACS NTDB website (https://www.facs.org/qualityprograms/trauma/tqp/center-programs/ntdb).

\section{Competing interests}

We know of no conflicts of interests associated with the publication and there has been no financial support for this work that could influence its outcome.

\section{Funding}

There was no outside financial support for the production of this article.

\section{Authors' contributions}

$\mathrm{CF}$ and XD completed data collection. CF and CV performed statistical analysis. CF, BC, BS, and CHP wrote the manuscript. CHP was senior mentor for this paper. The authors read and approved the final manuscript.

\section{Acknowledgements}

Not applicable

\section{References}

1. Grinshteyn E, Hemenway D. Violent death rates in the US compared to those of the other high-income countries, 2015. Prev Med. 2019 Jun;123:20-26. doi: 10.1016/j.ypmed.2019.02.026. Epub 2019 Feb 25. PMID: 30817955.

2. Centers for Disease Control and Prevention (CDC). WISQARS (Web-based Injury Statistics Query and Reporting System)|Injury Center|CDC.https://www.cdc.gov/injury/wisqars/index.html (December 02, 2021). Last accessed January 14, 2022.

3. American College of Surgeons. Annual Call for Data: National Trauma Data Bank (NTDB).https://www.facs.org/quality-programs/trauma/tqp/center-programs/ntdb. Last accessed January 14, 2022.

4. Data Bank (NTDB). JAMA Surg. 2018 Sep 1;153(9):852-853. doi: 10.1001/jamasurg.2018.0483. PMID: 29617536.

5. Hink AB, Bonne S, Levy M, Kuhls DA, Allee L, Burke PA, Sakran JV, Bulger EM, Stewart RM. Firearm injury research and epidemiology: A review of the data, their limitations, and how trauma centers can improve firearm injury research. J Trauma Acute Care Surg. 2019 Sep;87(3):678-689. doi: 10.1097/TA.0000000000002330. PMID: 31033891. 
6. Branas CC, Richmond TS, Schwab CW. Firearm homicide and firearm suicide: opposite but equal. Public Health Rep. 2004 Mar-Apr;119(2):114-24. doi: 10.1177/003335490411900203. PMID: 15192897; PMCID: PMC1497617.

7. Manley NR, Croce MA, Fischer PE, Crowe DE, Goines JH, Sharpe JP, Fabian TC, Magnotti LJ. Evolution of Firearm Violence over 20 Years: Integrating Law Enforcement and Clinical Data. J Am Coll Surg. 2019 Apr;228(4):427-434. doi: 10.1016/j.jamcollsurg.2018.12.033. Epub 2019 Jan 28. PMID: 30703539.

8. Livingston DH, Lavery RF, Lopreiato MC, Lavery DF, Passannante MR. Unrelenting violence: an analysis of 6,322 gunshot wound patients at a Level I trauma center. J Trauma Acute Care Surg. 2014 Jan;76(1):2-9; discussion 9-11. doi: 10.1097/TA.0b013e3182ab19e7. PMID: 24368351.

9. Fowler KA, Dahlberg LL, Haileyesus T, Annest JL. Firearm injuries in the United States. Prev Med. 2015 Oct;79:5-14. doi: 10.1016/j.ypmed.2015.06.002. Epub 2015 Jun 24. PMID: 26116133; PMCID: PMC4700838.

10. Conner A, Azrael D, Miller M. Suicide Case-Fatality Rates in the United States, 2007 to 2014: A Nationwide Population-Based Study. Ann Intern Med. 2019 Dec 17;171(12):885-895. doi: 10.7326/M19-1324. Epub 2019 Dec 3. PMID: 31791066.

11. Goldstick JE, Carter PM, Cunningham RM. Current Epidemiological Trends in Firearm Mortality in the United States. JAMA Psychiatry. 2021 Mar 1;78(3):241-242. doi: 10.1001/jamapsychiatry.2020.2986. PMID: 32965479; PMCID: PMC7933080.

12. Tasigiorgos S, Economopoulos KP, Winfield RD, Sakran JV. Firearm Injury in the United States: An Overview of an Evolving Public Health Problem. J Am Coll Surg. 2015 Dec;221(6):1005-14. doi: 10.1016/j.jamcollsurg.2015.08.430. Epub 2015 Sep 12. PMID: 26422747.

13. Watson D, Benton B, Ablah E, Lightwine K, Lusk R, Okut H, Bui T, Haan JM. Demographics and Incident Location of Traumatic Injuries at a Single Level I Trauma Center. Kans J Med. 2021 Jan 21;14:5-11. doi: 10.17161/kjm.vol1413771. PMID: 33643521; PMCID: PMC7833984.

14. Guetschow B, Lilienthal M, Willey M. Unintentional Firearm Injuries Remain Prevalent Over a 12 Year Experience at a Rural Midwestern Level 1 Trauma Center. lowa Orthop J. 2018;38:45-52. PMID: 30104924; PMCID: PMC6047385.

15. Choron RL, Spitzer S, Sakran JV. Firearm Violence in America: Is There a Solution? Adv Surg. 2019 Sep;53:195-208. doi: 10.1016/j.yasu.2019.04.019. Epub 2019 May 23. PMID: 31327446.

16. Papadopoulos FC, Skalkidou A, Sergentanis TN, Kyllekidis S, Ekselius L, Petridou ET. Preventing suicide and homicide in the United States: the potential benefit in human lives. Psychiatry Res. 2009 Sep 30;169(2):154-8. doi: 10.1016/j.psychres.2008.06.038. Epub 2009 Jul 30. PMID: 19646765.

17. Anglemyer A, Horvath T, Rutherford G. The accessibility of firearms and risk for suicide and homicide victimization among household members: a systematic review and meta-analysis. Ann Intern Med. 2014 Jan 21;160(2):101-10. doi: 10.7326/M13-1301. Erratum in: Ann Intern Med. 2014 May 6;160(9):658-9. PMID: 24592495. 
18. Cook PJ, Lawrence BA, Ludwig J, Miller TR. The medical costs of gunshot injuries in the United States. JAMA. 1999 Aug 4;282(5):447-54. doi: 10.1001/jama.282.5.447. PMID: 10442660.

19. Lee J, Quraishi SA, Bhatnagar S, Zafonte RD, Masiakos PT. The economic cost of firearm-related injuries in the United States from 2006 to 2010. Surgery. 2014 May;155(5):894-8. doi: 10.1016/j.surg.2014.02.011. Epub 2014 Feb 22. PMID: 24684950. 